\title{
The Enacted Ethics of Self-injury
}

\author{
Zsuzsanna Chappell ${ }^{1}$
}

Accepted: 22 January 2022 / Published online: 11 February 2022

(c) The Author(s), under exclusive licence to Springer Nature B.V. 2022

\begin{abstract}
Enactivism has much to offer to moral, social and political philosophy through giving a new perspective on existing ethical problems and improving our understanding of morally ambiguous behaviours. I illustrate this through the case of self-injury, a common problematic behaviour which has so far received little philosophical attention. My aim in this paper has been to use ideas from enactivism in order to explore self-injury without assuming a priori that it is morally or socially wrong under all circumstances, seeking to establish a less implicitly value-laden analysis. Enactivism can help us in making this behaviour more intelligible and contextualising it through examining the relations of individual embodied action and social practices with the help of enactivist theories of habits and affordances.
\end{abstract}

Keywords Applied ethics $\cdot$ Enactivism $\cdot$ Reason $\cdot$ Self-injury

\section{Introduction}

Enactivist theories are already proving useful in areas such as philosophy of emotion (Colombetti 2014), philosophy of joint action (Gallagher 2020), skilled action (Cappuccio et al. 2020; Rucińska 2021), philosophy of music (Krueger 2014; Schiavio et al. 2017), philosophy of psychiatry (de Haan 2020; Glas 2020; Nielsen 2021) and bioethics (Svenaeus 2021). A key questions is whether this usefulness can be extended to areas of philosophy that fall under the label of value theory, namely moral, social and political philosophy and aesthetics. The aim of this essay is to explore the potential enactivism has for contributing to the field of applied ethics. As such, it is written from the perspective of applied ethics carried out in the analytic tradition looking for potentialities in enactivism, rather than the other way around.

Rather than focusing on enactivism's implications on meta-ethics, the structure of our ethical theorising itself, in this paper I want to draw out another way in which enactivist theories can have a significant impact on this area of philosophy. Many ethical puzzles owe their existence to the fact that we are not perfectly rational, ideal agents. We are forgetful, myopic, akratic, experience addictions, emotions which cannot be rationalised, and are prone to acting

Zsuzsanna Chappell

zsuzsanna.chappell@gmail.com

1 Independent Scholar, London, UK "out of character". At times it is almost as if we have to work around a black box of irrationality, which impedes our progress at every turn. Cognitive philosophy can help us in unlocking this black box. Furthermore, we want to unlock our black box in a relatively value neutral way. While we may acknowledge that no theory is able to achieve complete value neutrality, we can strive to reduce inherent biases. Myopia, akrasia, forgetfulness, addiction are all negatively loaded terms; they are not just a puzzle to solve, their negative consequences are usually implicit in the language we use. They impede rationality, particularly understood as the instrumental rationality of adopting suitable means for achieving our ends. I believe that enactivism could offer us a relatively less value-laden alternative for explaining such seemingly irrational behaviour.

The ethical implications of enactivist theories have already provided interesting insights. An explicit discussion between enactivism and ethics was initiated by Colombetti and Torrance (2009) over ten years ago. Van Grunsven (2018) started an important enactivist engagement with the topic of agency and responsibility. Enactivist bases of the joint action required by morality, law and politics are discussed by di Paolo et al. (2018) and Gallagher (2020). Enactivism has lead thinkers towards feminist theories of care ethics (Urban 2016; Van Grunsven 2018, Loaiza 2019), which examine the links of justice to interpersonal, embodied relations. Urban argues that theories of care ethics are closest to a "genuinely relational phenomenological ethics" 
(2016, p. 172). Enactivist theories of skilled action also mirror the process of virtue acquisition which is foregrounded by virtue ethicists (Annas 2008; DeSouza 2013).

In order to examine how enactivism could explain initially unintelligible behaviours in a relatively value-neutral way, I will discuss the social and moral norms around deliberate self-injury as a case study. This topic has been relatively neglected in ethics, even though it is similar to issues discussed in greater detail, such as suicide (Cholbi 2011), addiction (Pickard 2020) and eating disorders (Giordano 2019). Given their link to the philosophy of psychiatry, where enactivism is already proving to be influential (e.g. de Haan 2020; Nielsen 2021), these issues are a good starting point for the interaction of enactivism with value theory. I turned to enactivism myself when, working on the ethics of self-harm, I needed a way of thinking through some of the problems evidenced by the behaviour. Selfinjury is usually described from the start in normatively laden terms as dysregulated or dysfunctional behaviour. While I believe that self-injury is undoubtedly bad and not to be encouraged, it is also important to engage with it in a more value-neutral way in our research, a way that not only focuses on and pathologises individual cognition, but pays attention to the entire body-mind, embedded in a social and material environment.

In Sect. 2 I will provide a brief overview of enactivism. In Sect. 3, I will provide a definition of self-injury and illustrate the kinds of ethical problems it poses. In Sects. 4 and 5 I focus on two key concepts from enactivism to see how we could understand self-injury better: habits and affordances. In Sect. 6 I will briefly discuss the broader implications of using enactivism in order to extend the range of mutually intelligible behaviours.

\section{Enactivism}

Just as we would expect from a rapidly developing field, there are variations in the ways in which different scholars use the term 'enactivism' (cf Kiverstein and Clark 2009). The roots of enactivist theories lie in ecological psychology and cognitive science (Varela 1999), and in classical phenomenology, especially the works of Merleau-Ponty (di Paolo et al. 2018). At first sight, maybe at the point when theories of enactivism tell us how bacteria will float up in liquid following a sugar gradient, it may be difficult to see how ethics would benefit from such theorising, unless we are addressing the question of value-formation (or why the bacteria should value pursuing the dissolved nutrients).

Enactivism encourages seeing ourselves, as humans, also as bounded organisms comprised of both body and mind and placed into a social and physical environment with which we need to interact and which constrains the values we may form. ${ }^{1}$ Yet while this environment forms us and constrains our choices, it also offers us possibilities for action, and we can shape our environment in line with our values. Thus we are not mere passive experiencers receiving values from our environment. "The organism is the centre of activity in the world" (de Jaegher and Di Paolo 2007, p. 487): an autonomous agent not limited to responding to environmental stimuli and satisfying internal demands.

Organisms do not passively receive information from their environments, which they then translate into internal representations whose significant value is to be added later. Natural cognitive systems are simply not in the business of accessing their world in order to build accurate pictures of it. They actively participate in the generation of meaning in what matters to them; they enact a world. (de Jaegher and di Paolo 2007, p. 488, emphasis added)

Our environment is dynamic rather than static; it is constantly changing. Natural forces, non-human animals and humans all contribute to this ongoing change. Part of the challenge for each of us is then to adapt to this world in flux. For us humans, since we are not only embodied but also moral animals, one of the criteria of successful adaptation will be moral ${ }^{2}$ (e.g. MacIntyre 2009). Not only do we want to succeed as biological organisms, we also want to live according to our notions of justice and the good life, the right and the good. Thus our aims are significantly more complex than that of bacteria pursuing nutrition.

Applied ethics focuses on particular, problematic real world situations. As a result it encompasses the intersection of the empirically knowable material world (our world) and moral-philosophical theories, principles, and ideals (the way we ought to enact a world). Nearly all areas of applied ethics have a strong embodied component: reproductive ethics, the ethics of disability, parenting, food or the environment are just a few examples. Furthermore, ethics is naturally a relational enterprise. Much of it asks questions about how we ought to treat people, including ourselves. Even when we think and write about individual conceptions of the good life or the ethics of environment, we have to acknowledge that the way we live our lives, the way we treat our environment will always have implications for the people with whom we share our world and for future generations who will inherit it from us.

Ethical accounts often take up problems that occur when inter-personal sense-making breaks down. As an example, we discuss issues of responsibility and agency exactly

\footnotetext{
1 In Hume's famous terms: ought implies can.

2 The extent to which some non-human animals might enact some form of morality is an open question.
} 
because we are not always sure when agents are responsible for their actions and when they are not. We need to work out how to best make sense of the actions of others in order to be able to apply moral terms such as responsibility to those actions. Of course, intra-personal (within person) sensemaking can also break down, which is what makes akrasia or weakness of the will such enduring puzzles. In these cases, we do not understand our own actions. Enactivism could serve an explanatory function where current explanations are weak or fail by explaining these issues better in a way that does not prejudge their moral evaluation.

Concepts such as affordances and habits, which I will discuss in more details in later sections of this paper, can be incorporated into larger frameworks that study enaction within a social and cultural setting. One example of this is the skilled intentionality framework (Rietveld and Kiverstein 2014; van Dijk and Rietveld 2017). These philosophers argue that skilled individuals have learnt to respond appropriately to the sociomaterial practices they are part of, the cultural world which they inhabit. So far, such theories have for the most part assumed that following social rules and norms of behaviours is uncomplicated from a morally normative perspective (Rietveld and Kiverstein 2014; Mojica and Gastelum Vargas 2021). Thus, adhering to such norms is seen as largely beneficial for individual agents (Mojica and Gastelum Vargas 2021) and serves to enable a flourishing life.

Yet, the assumption of skilled intentionality simply consisting of following socially normative behaviour needs to be problematised when we are dealing with morally ambiguous behaviour or in pluralistic societies where communities with different sociomaterial cultures live side-by-side. In these cases, the question is exactly what constitutes a skilled response. When there is disagreement about what that response should be, mutual sense-making can even break down when one group does not even try to make sense of the meaning of actions when those meanings are not readily available to them (Schutte 1998). Enactivism can be a useful tool for analysing the way in which meanings can be thus lost between people.

This becomes apparent when we consider the problem of self-injury. Agents who self-injure are usually seen as impulsive and compromised in their agency. While this may be true, this ignores the fact that self-injury takes place in the context of distress, mostly caused by social factors outside the agent's direct control. Not only is self-harm related to agents' social situation, but it can be seen as both provided and prohibited by the same social discourse. It is a case little explored in the ethical literature (exceptions include Pickard 2015; Kong 2019), and it is difficult to interpret within existing frameworks. Thus it is exactly the kind of ethical problem which would benefit from an enactivist approach.

\section{Self-harm as Self-injury}

Most would place self-harm on the side of morally, rather than culturally prohibited behaviours. Thus they would say that it is always wrong, rather than that it is wrong within the context of their society's culture. The basis of this belief is relatively little explored. The first question of ethics to ask here is: on what grounds can we interfere with the selfdirected behaviour of others? If self-harm is not morally wrong, then (apart from social customs, which may be unjust or unfair) its wrongness may be grounded in the badness of the action or its consequences: it is wrong to treat ourselves in a way that feels and looks quite this bad. We are usually careful to avoid harm and injury. We tend to think that there are very few reasons that trump preserving bodily integrity. These reasons are usually about avoiding even greater injury either in another, for example when someone risks being hit by a bullet to save someone else, or in ourselves, as when someone cuts off a foot to free themselves from being trapped under a boulder. ${ }^{3}$

This leads us to a second ethical question: what constitutes a good relationship with our embodied selves? A big part of the puzzle is why self-harm should be regarded as so much worse than other things we do which are bad for our bodies, but from which we do derive some kind of benefit or satisfaction, such as eating too much unhealthy food or smoking cigarettes. Yet to most, unlike these kinds of damaging behaviours, self-harm appears as particularly difficult to understand or even unimaginable, making it imperative that any good theory of self-harm should make the phenomenon more comprehensible. Not understanding self-injury can lead us to assume a priori that something that is bad is also wrong, thus apportioning blame even before considering the relevant facts.

The most familiar form of self-harm is deliberate selfinjury. While its notoriety has waxed and waned over time (Chaney 2019), discussions about and depictions of selfinjury have become a familiar element of contemporary Western culture over recent decades (Steggals 2015; Brossard 2018). Self-injury is usually defined as intentional tissue damage. Cutting, hitting, bruising, hair pulling, biting, taking a non-fatal overdose of medication, burning, swallowing objects or otherwise inserting them into the body are all common examples of self-injury. Among these cutting is currently the most commonly reported (Chandler 2016) and self-poisoning is not included under all definitions.

Thinking superficially, we may believe that someone who self-injures does so for the sake of the injury,- the overall

\footnotetext{
3 There may be other acceptable reasons in other (sub)cultures, for example linked to religious rituals where injuries contribute to religious ecstasy or insight.
} 
experience of it,- -rather than for the relief it brings. Yet self-harm, as it is currently defined, is not primarily about masochism or enjoying getting injured. Even people who do not enjoy getting injured may find purpose in self-harm (Sutton 2007). While self-harm is a very heterogenous behaviour, as people can have different motives for, explanations and methods of self-injury, the recent empirical literature does reveal a broad picture of contemporary practices of self-harm (e.g. Brossard 2018; Chandler 2016; Sutton 2007; Steggals 2015). Much of the time, self-injuring seems to resemble taking over-the-counter or prescription medicine against pain, more than it resembles taking illegal drugs for the high they cause. ${ }^{4}$ While taking paracetamol for a mild headache is an indifferent experience in itself, I do not enjoy taking a stronger prescription pill for my migraine as it makes me feel drowsy and foggy. I would not take either just for their own sakes, as they are not beneficial for my body all things considered, without the presence of pain. Equally, self-injury is usually not beneficial in itself. Of course, just as someone can become addicted to pain killers, one can also become addicted to self-injury. One may also take painkillers compulsively, or not realise that what they are eating are painkillers, rather than candy. Equally, someone could develop a compulsion to injure themselves, or they might drink poison in the mistaken belief that it is medicine. These are, however, cases of addiction, compulsion, mistaken belief or delusion, cases which a basic analysis of self-injury needs to explicitly exclude. But neither is harm or injury an unwanted side-effect of self-harm. The smoker smokes because they are addicted to nicotine, enjoys smoking or wants to fit into their peer group, and is only incidentally damaging their lungs in the process. The adrenaline junky may engage in risky extreme sports and the risk of injury is part of the thrill, but their aim is not to get injured, so that they can repeat the experience. By contrast, the person who self-harms would be focused on injuring their lung or actively risking injury through extreme sports and any other benefit, such as actually enjoying extreme sports, would be at most a secondary consideration.

Self-harm as self-injury can point towards numerous psychiatric disorders, including depression, anxiety and personality disorders, but while it is usually an expression of mental distress, it is not always a sign of mental disorder (Sutton 2007) and can easily go undetected by others. Its prevalence in Western societies is high, although difficult to estimate given its hidden nature. A meta-analysis by Muehlenkamp et al. (2012) put the prevalence rates at $16.1 \%$ or 18\% among adolescents studied between 2005 and 2011. Klonsky (2011) found that $5.9 \%$ of adults in the United

\footnotetext{
${ }^{4}$ Of course someone might also later on come to consume drugs in order to avoid withdrawal symptoms.
}

States had self-harmed. Despite the common stereotype, self-injurious behaviours are not limited to adolescent girls, even though it appears that the majority of those who report self-injuring are young and female (Sutton 2007).

Reasons provided for self-harm are diverse, though they appear to stem from experiences of distress. The most common motivation cited in the empirical research literature is emotional regulation or a "pathological soothing mechanism" (Herman 2015, p. 109): coping with emotions that seem unbearably intense or trying to jolt the self out of the numbness of emotional dissociation (Pickard 2015, Rossi Monti et al. 2019). Other reasons include self-punishment, re-enacting trauma or responding to loss of control. Not all reasons for self-harm, however, are negative, even within this context of distress. Testimonies from those who selfharm show that it is also seen as a way of taking control, enacting agency, whether it is through experiencing pain on one's own terms or creating permanent reminders and shaping the body through scars (Chandler 2016). ${ }^{6}$ For some, it is the self-care administered when looking after their injuries that has the greatest significance. For others, the body mirroring the state of the mind holds an aesthetic significance. Many of those who self-injure report that they do so exactly in order to counter suicidal ideation (Motz 2010), even if on rare occasions they might in fact put themselves into dangerous situations where it is no longer clear, even in the mind of the agent, whether the intention was to self-harm or to attempt suicide (Brooke and Horn 2010). It is likely that those who self-harm will turn to culturally sanctioned interpretations when they seek to explain their behaviour to themselves and others (Steggals 2015). Thus there may be a gap between the intentionality of the agent enacting the selfinjury and the same agent explaining the self-injury later to themselves and others. There is still a need for empirical research that unpacks how these behaviours are enacted, as current evidence from individual testimonies does not yet provide a full explanation for them. As self-injury is such a heterogeneous behaviour both in terms of motivation and method, it is also difficult to generalise from specific examples.

One way of approaching this problem is through adopting the enactive model of agency developed by Gallagher (2020), who differentiates between three different levels of agency, following the model developed by Pacherie (2008). The first type is distal intentionality (D-intentions): planned action agents resolve themselves on in advance. Someone

\footnotetext{
$\overline{5}$ Once again, this raises the question what makes this soothing mechanism particularly pathological, compared to say eating a tub of ice cream.

${ }^{6}$ More empirical research is needed in order to establish how this plays out in practice, without which we can only speculate.
} 
may decide to stop self-harming, or they may plan for selfharm in a ritualistic fashion, for example through purchasing a supply of clean blades and bandages. In the moment when the urge to harm oneself appears, such deliberations may become less important, as in the moment, habitual proximalintentionality (P-intentionality) and basic motor intentionality (M-intentionality) take centre stage, over-riding more careful deliberative impulses. P-intentions do not necessarily inherit the action plan of D-intentions. This type of intentions serve to anchor intentions to specific situations. Thus they respond to the current situation as the agents perceives it to be, which may over-ride previous D-intentions. In the case of self-injury this could mean the immediate distress and accompanying urge to harm oneself may over-ride earlier plans to abstain and habitual action is initiated instead and carried out through basic M-intention. Retrospectively, these may be turned into a more coherent narrative of emotional management or mismanagement reflecting cultural practices of sense-making.

Despite its badness, self-harm is arguably not morally wrong. Duties towards oneself against self-injury and suicide that are grounded in respecting one's own humanity and dignity (Kant 1797/1996, Pickard 2015) can be difficult to establish (e.g. Muñoz 2020). Any duty with which I bind myself can equally be over-ridden by my right to deal with my body as I will. If an agent is in severe, acute distress and they are unable to respond to this in any other meaningful manner, then refraining from self-injury may even be more harmful and damaging to autonomy and dignity as it leaves them in continued distress. This could put self-injury in line with other ways of damaging our bodily integrity that are acceptable because we are trying to avoid greater harm or injury. This may be particularly the case for those who say that self-injury helps them to manage suicidal ideation. Requiring people to stop self-injuring without examining the meaning of the practice may lead people towards more damaging alternatives such as over-eating or excessive dieting (Brossard 2018) as they will still need to deal with their distress in some way and there are no guarantees that this will be a healthier one.

Moral considerations towards others, through an appeal to the harm principle, are also problematic as a basis for establishing that self-injury is wrong. In the large majority of cases those who self-injure deny that they do so in order to communicate with others, which is borne out by the fact that self-injury tends to be carefully (although not always successfully) hidden ${ }^{7}$ (Brossard 2018). As long as those who self-injure take reasonable precautions in how they appear in front of potential witnesses and bystanders and are careful of

\footnotetext{
7 This should be differentiated from communicating about one's selfinjury, for example in an online support group or in therapy. The aim of the act itself is most often not communicative or manipulative.
}

how they talk about it to vulnerable others, it is difficult to show that self-injury is harmful to others, rather than simply offensive.

This does not mean that self-injury is something we should acquiesce in, let alone promote, just as we want to reduce other self-damaging behaviours such as drug addiction, smoking or a poor diet. But we need to be more aware of the social circumstances that may lead to both self-injury and its condemnation, and the individual distress it originates in. Ultimately, what needs to be eliminated is the underlying pain and distress, instead of simply focusing on erasing a behaviour that society strongly disapproves of.

Viewing such behaviour through the enactivist lens may also help us change what aspects of self-injury we pay attention to. This allows us to develop a picture of self-injury that is not focused only on a pathological behaviour, but takes a broader view of it as an embodied activity embedded in culture (Clarke \& Whittaker 1998). This mirrors the approach of the skilled intentionality framework in locating actions within a landscape of sociomaterial practices (van Dijk and Rietveld 2017). In fact, this paper has grown out of my own difficulties in thinking self-injury in a relatively formal way, while discussing the ethical issues surrounding it.

In Sects. 3 and 4 I will examine the way in which two important enactivist concepts-habits and affordances-can make self-injury less mysterious and unintelligible. The habitual nature of self-injury simultaneously captures some of our deepest concerns about the behaviour, while also pointing to why it is so difficult to change self-harm behaviours. Thus, the concept of habits helps us to dig deeper in understanding the implications of the individualist aspects of self-harm we are currently focused on. Affordances, on the other hand help us change the focus of our attention and move it away from the individual in distress to how our environment solicits quick and dirty distress management through self-injury.

\section{Individual Habitual Action}

Our everyday ambivalence about habits is displayed by the fact that we think of them both as mindless, as when we are brewing morning coffee, and as something for which people can be held responsible, as in addiction and self-injury. Selfinjury is not only engagement with our surroundings and our bodies, but it is habitual engagement. It is rarely a oneoff action and instead becomes part of a regular repertoire of skilled action aimed at dealing with distress. Sometimes this distress may even be quite mild, such as the discomfort caused by boredom (Brossard 2018). Thus self-injury can be likened to other forms of habitual skilled performance which can be performed without deliberation (Ramírez-Vizcaya and Froese 2019). It is this habitual character which often 
causes the greatest worry to others. Even when it functions as intended-relieving distress, —-self-injury remains a suboptimal behaviour according to most measures and bad for us in itself. A good analogy when we are arguing against self-injury would be to say that drinking sugary drinks may alleviate thirst as well as water, but we consider water a healthier alternative.

Habits can be seen as non-intellectual short-cuts that simplify regular tasks. They can also be counter-productive to our stated goals and intentions (Miyahara and Robertson 2021). Yet, mindlessness does not fully capture how we think about habits, as we also tend to link habit to character (Annas 2008; Maiese 2021). A virtuous person cultivates virtuous behaviour, and if we think that self-injury is a vice, then it is not only an unpleasant habit, but a sign that we are not able to deal with our problems "the right way" (Chandler 2016), we are not sufficiently skilled at choosing the normatively correct response to our situation from the repertoire of responses made available to us by our social and material environment (Rietveld and Kiverstein 2014). Thus there is something lacking in our character; we are lacking as persons. This clearly invites normative judgment. Even if habits are mindless day-to-day, agentic control is present at the point of cultivating habits, rather than at the point of enacting them. Linking disgusting habits to a lack of character may help to explain stigmatisation as well as concerns about "epidemics" and contagion.

As well as a sign of poor character, self-injury is also seen as an urge, as a complete failure of self-control, negating responsibility, especially if we have "caught" it from someone else. Yet when patients say, and psychologists write that self-injury is compulsive, they usually mean that the urge to self-injure is very hard to resist, rather than that it is impossible to do so. Neither is self-injury an addiction in the sense that it causes withdrawal symptoms. This comes through clearly in an account by Rita Binns, who stopped self-harming because she was concerned about the impact of $A \& E$ attendance during the coronavirus pandemic (Binns 2020), and in accounts of people refraining from self-harm in front of others and especially in front of children (Pickard 2015). These agents are in fact responding skilfully to the sociomaterial practices that they are part of (van Dijk and Rietveld 2017). This is reflected in definitions of self-injury as "deliberate". It encompasses cases where agents are not either globally or locally unable to make rational decisions, are not coerced, are not under the influence of psychotropic drugs or suffering from psychotic delusions, and are aware of the consequences of their actions. Many of those who self-injure will plan the action in advance, keeping a selfinjury kit including blades or bandages. Others plan selfinjury and possible need for hospital attendance around their working hours (Brossard 2018).
Remedying self-harm is not as simple as exchanging one habitual action for another. Some habitual actions suggested as alternatives to self-injury may in themselves be culturally acceptable forms of self-harm, such as snapping rubber bands, pinching oneself or holding ice cubes (Sutton 2007). Other, more socially acceptable forms of self-harm may still be an unhealthy choices; for example eating to the point of discomfort.

Any habitual, skilful action is developed over time and then repeatedly enacted and re-enacted. Action becomes easier over time and acquires fluidity. As they are automatic and quickly responsive, habits can be deployed without reflective, conscious thought, but need not be blind and rigid, given that they respond to specific situations. Habitual action may be "intelligent and flexible while involving no deliberate action control and no explicit representation of the action goals" (Cappuccio et al. 2020 p. 610). When in a situation which someone finds extremely distressing, these habitual actions can over-ride more conscious decision-making processes. Indeed, the pressing nature of the distressing stimulus and the urge to alleviate distress that goes with it will reduce an agent's ability to formulate and carry out alternative actions. Thus self-injury will be considerably advantaged over other distress-management strategies that do not provide relief as quickly and as seamlessly. The higher the cost of alternative strategies in terms of loss of fluidity and skilfulness (that is, slower, more stumbling action) the lower the chance that the alternative strategy will prevail.

Through acquiring fluidity, an action also increases the sense it makes. It is not only that self-injury is practically somewhat easier to carry out. It also acquires meaning for agents as it is repeated over time, through a sedimentation of past actions, emotions and situations. By contrast, other actions, such as holding an ice cube, will feel alien. They may even hold meanings which negate any affective benefits: a mother who regularly puts the hairbands that her daughter would otherwise lose on her wrist may very well develop associations which make snapping a rubber band on her wrist infeasible as an innocuous, socially skilful form of self-harm. This last example also illustrates that habits are usually situated among a network of habits (RamírezVizcaya and Froese 2019), which give meaning to each other reflexively. The moment of self-injury often does not stand on its own, but is part of a network of behaviours. Someone purchasing razor blades or bandages at the chemist's shop could do this as part of a mundane shopping trip for household basics, or they may be stocking up their self-harm kit. Equally, someone who does not keep such a kit but uses readily available household objects expresses something about their particular way of using self-injury as less formalised and more contingent.

It is only when someone finds a strategy for alleviating distress that is genuinely meaningful within this wider 
context of behaviours can that strategy start to replace selfinjury. Problematically, these can involve not just healthier forms of self-soothing, but even more damaging behaviours such as over-eating, excessive dieting or over-exercising (Brossard 2018). This could, in our initial approach to managing self-injury, weigh in favour of ethical theories of harm reduction rather than outright prohibition: keeping in place safer ways of self-injuring until the underlying distress is addressed or new meaningful forms of distress management are created, and also appreciating the value that such a practice as a whole has for the agent. Thus behaviours like selfinjury remain ambiguous. While not morally wrong, their possible right-making features are not easily generalisable, and others may require to perform imaginative work in order to enable them to recognise theses in the first place.

This brief discussion of self-injury as habitual action may already help us in clarifying some of our existing worries about self-injury and some of the reasons why it is a difficult behaviour to change. Still, focusing on self-injury as individual, habitual action maintains and only expands on existing explanations. Yet I believe that enactivism can offer us even greater explanatory power and new ways of thinking about self-injury, by turning our attention to the way in which both our material and social worlds offer up the option of self-harm to distressed agents. For this, I now turn to the concept of affordances.

\section{Environment and Affordances}

In Sect. 3, I defined self-injury as intentional tissue damage to one's body carried out in order to cope with a distressing situation. We can reformulate this in the following way: selfinjury is the agent's use of objects in their material environment to damage their bodies with the expectation that this will help them cope with a distressing situation. This allows me us to locate self-injury among the practices made available to us by our environment.

Enactivism has adopted the concept of affordances from ecological psychology to capture the opportunities for action offered to agents by the world around them (Rietveld and Kiverstein 2014; Krueger 2014; Colombetti and Krueger 2015; McClelland 2020). While there is more than one conception of affordances available, here I focus on the version developed by Rietveld and Kiverstein (2014) as it is a component of the framework of skilled intentionality introduced in Sect. 2 and helps me to position self-injury within a landscape of interrelated socio-material practices.

At a simple level, a pencil is grippable for me and chewable for my dog. This does not get us very far, as gripping and chewing are not the level of actions we are primarily interested in. Thus we can go on to say that a pencil (piece of soft graphite wrapped in wood) might offer my dog a good chew toy (it affords chewability), while it would appear to me primarily as something to write with (it affords grippability for the purposes of writing; it is a special kind of grippability that presupposes that I hold the pencil with a tripod grip). By saying "appears to me as" I am already indicating a process of sense-making: what is salient to me is not primarily that the pencil is grippable, but that it offers me a potentiality for writing. ${ }^{8}$

We can learn new ways of using our environment through experimentation or through information provided by others and thus broaden the range of affordances available to us. Children will start by making simple marks with a pencil, then move on to communicating through drawing objects and then writing, once they first learnt the relevant social system of symbols (Rietveld and Kiverstein 2014). ${ }^{9}$ Similarly, we can also lose affordances. Arthritis may stop someone from playing the piano; the piano (as an object) will no longer afford them the possibility of making music. Gaining and losing affordances may be of particular relevance to ethical issues, as it is in the case of self-injury. Many objects afford more than one possibility for use. A knife (which is grippable) can be used to cut up food, open a package, pry a lid lose, butcher an animal or self-injure. If I do not have food to cut up, a package to open, a lid to loosen or an animal to butcher, the knife does not at that time afford me the relevant action, as I lack the necessary combination of material objects in my environment. As a city-dweller, using a knife to butcher an animal is not an affordance I would consider knives to hold in the regular course of things. ${ }^{10}$ Similarly, for most of us, knives as material objects do not immediately present the opportunity for self-injury, as we are not in the state of distress which self-injury can address.

Our environment may not only afford self-injury, we may perceive it as actively soliciting it (Siegel 2014), just as we perceive a ringing phone not just an opportunity, but as an invitation or even a demand to answer it. Thus for many who self-injure, just seeing a knife might bring forth thoughts of further injury. As Rietveld and Kiverstein (2014) put it:

We suggest that is our current abilities and concerns that make it the case that we are solicited by one affordance rather than another. Moreover, once we have available the notion of a solicitation, we can also rec-

\footnotetext{
${ }^{8}$ This is consistent of McClelland's (2020) definition of affordances as "AFFORDANCE: $\mathrm{x}$ affords $\varphi$-ing for $\mathrm{S}$ iff $\mathrm{x}$ offers an opportunity for S to $\varphi . "$ (p. 403): a pencil affords writing for me iff the pencil offers an opportunity for me to write.

${ }^{9}$ Even this is an oversimplification. Since I started writing this paper, my daughter had started to play at writing by producing squiggles which were only intelligible to her. Then she moved on to writing recognisable characters from the Latin alphabet.

${ }^{10}$ Although the affordance is still inherent in the object even if it is not available to the agent (Rietveld and Kiverstein 2014).
} 
ognize how sometimes the world can motivate us to act in certain ways. When we experience a particular tendency to act in a certain way, this is because we have been solicited by one of the many possibilities for action available in our situation. (p. 342)

How do people come to realise that objects in their environment afford action that reduces distress through self-injury? Brossard (2018) argues that they do so either by accident or through a cultural learning process. Someone might realise that refusing to let an injury heal and making it worse is an outlet for certain kinds of feelings. Nowadays, when selfinjury is commonly discussed in the public sphere, people are much more likely to learn about the concept through cultural transmission, but will adapt the actual form their self-injury takes to their own circumstances. In everyday discourse this is often simplistically presented as vulnerable people starting to self-injure or being encouraged to continue self-injuring through being led astray by depictions of the act, most likely on social media. However, this story is much too simple.

We can observe self-injurious acts among captive animals who have no options to escape either loneliness or undesirable cage-mates, lack adequate mental stimulation and are not offered alternative ways for distress management (Breuning 2013). This implies that our environment affords opportunities for distress management through self-injury in itself, without any cultural baggage attached or learning required. In a classic anthropology paper Mauss (1973) notes that while common behaviours such as sleeping, walking, eating or swimming are carried out in all societies, their particular execution will vary according to social constraints. Similarly, Elias et al. (2000), in his masterful study of Western manners since medieval times, argues that common actions differ widely over time as cultures change; while in medieval England standing on one leg may have been considered normal, it would be seen as outlandish now, even though we do continue to stand frequently. Thus while self-injury may be present even in non-human animals, as members of various cultures humans will assign different significance to it and might enact the behaviour in culturally specific ways.

While self-injury seems to exist as a constant over time, various socially recognised outbreaks and epidemics over time have manifested differently (Chaney 2019). Thus, between the two world wars, there was a spate of cases of "needle girls", who self-harmed through inserting sewing needles in various ways into their bodies. Meanwhile, hospital and asylum records from nineteenth century England show that head banging, self-biting, self-scratching, hair pulling were common behaviours among patients, without attracting any special attention from physicians or the wider culture. In our early twenty-first century society people do not need to discover the relief offered by self-injury by accident, they are provided with a ready-made model of how to self-injure, primarily through cutting (Brossard 2018). Self-injury is positioned as a viable method for our urges towards managing our distress through its portrayal in entertainment, the media and public discourse (Steggals 2015). Given this cultural context, enactivism can help us to re-frame self-injury as an affordance embedded within a cultural system, a skilled socio-material practice.

Also relevant here is Hacking's work (1998) on environmental niches that allow transient mental health epidemics to develop, such as an outbreak of supposedly hysterical fugues in the late nineteenth century or multiple personality disorder in the twentieth century. Hacking argues that such patterns of disordered behaviour emerge when there is a framework of diagnosis in the mental health system within which the behaviour will neatly fit, the behaviour becomes easily observable, it is situated in an ambiguous position between virtue and vice and it provides release which is "not available elsewhere in the culture within it thrives" (p. 2). When we assess it against these criteria, self-harm fits neatly in contemporary understandings of emotional regulation and even trauma. The internet has made self-injury much more visible and has given a means for people to connect online to discuss it. It is situated within a broader acceptance of body modification, whether in the form of tattoos or botox, and it also rebels against the pressure to present an airbrushed, picture-perfect body. Finally, it does appear to offer release to those practicing it. These elements do not make self-injury unique to our society, but they could explain its relative prominence. Hacking discusses the case of hysterical fugeurs, mostly men who took to the road and travelled long distances in France at the end of the nineteenth century, often claiming little memory of or control over their behaviour. People have wandered off from home before and since, and have started new lives, but their behaviour did not have the same social and cultural significance it had during that specific historical time and place.

Through its sociocultural meaning self-injury has retained its significance as a coping mechanism, but has also acquired additional meaning as a dangerous, deviant epidemic. In this cultural context, self-injury is presented fundamentally ambiguously, as it is simultaneously forbidden as repugnant, habitual, contagious, and advertised as something to turn to at times of psychological distress. To adapt an argument Seaber (2016) makes about the depiction of eating disorders: while someone not in distress, afraid of injuries or with a low pain threshold might see self-injury as pre-reflexively wrong for themselves and repugnant for others, someone with a different outlook and needs may re-interpret cautionary warnings as useful guidelines or even aspirational instructions. The second person can come to see affordances for self-injury in their environment (a knife becomes a possible tool for managing emotions), while the first person 
will not learn to do so. This explains why simply becoming aware of self-injury, for example through social media, does not necessarily socialise someone into self-injury. The skilled use of affordances means that the agent understands that self-injury is to be used to deal with distress, just as on a more mundane level a skilled agent understands that we stand on a chair to change a light bulb but not to eat our dinner.

Through its simultaneous prohibition and promotion the act of self-injury acquires layers of meaning: not only is it a way of dealing with distress, it is a particularly culturally charged way of doing so. This is not inherent in the material object but it is inseparably added to the affordance it offers once the agent is aware of it through being immersed in the relevant cultural context and its landscape of affordances. ${ }^{11}$ Someone self-injuring once they have learned the cultural significance of their behaviour will be performing a different action from someone who does not know that there are other people who also self-injure, or that it is a largely forbidden action.

A point worth considering is that self-injury reveals a way in which our own bodies afford actions just as other material objects around us do. ${ }^{12}$ After all, at its most simple, self-injury requires no other object, as it can be carried out through scratching, hitting, biting or hair-pulling. This is the body used as a dual instrument: a tool for causing and an object for receiving pain. To this extent it highlights a disturbing duality of our bodies and the attitudes we can take towards them.

By creating scars, and so on, we create further affordances-something through which our bodies and distress can be contemplated at one remove (see McClelland 2020 for a theory of mental affordances). Visible marks and injuries may allow us to express and display distress. It may allow us to take back control, as self-injury is often carried out in situations where someone has little control over their lives or their emotions. By marking our bodies-whether with a new haircut, tattoos or self-injury scars-we signal a form of ownership over it and mark its individuality. Even if self-injury is carried out as a primarily secret behaviour, scars can communicate past experience of distress even after long periods of time. And even as we are discovering and creating potentialities our own body can afford, we will have an effect on others. The meaning and interpretation these

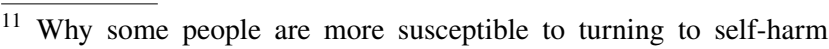
than others is something that still needs to be established through empirical research.

12 Husserl (2012) and Merleu-Ponty (1968) also discuss the tensions inherent in our bodies acting simultaneously as subjects and objects of our conscious experience through the image of our hands touching each other, where the gap between touching and being touched can never be quite bridged.
}

others give to our actions and our bodies will then escape us, be out of our hands. In turn these others may fail to see the original meaning in our behaviour, and instead make sense of it according to their own interpretations, foreclosing the possibility of genuine interpersonal sense-making.

If self-injury is a fundamentally embodied action, reactions to it of disgust, revulsion and repugnance are also fundamentally embodied. To a large extent, these are visceral reactions to sights which are the indication of danger: rotting food, injuries, putrefaction all signal that something can go badly wrong for us here. But as Mary Douglas (1966) has shown, we can learn to extend disgust to culturally constructed sources of dangerous impurity. Under our current cultural conception of psychological and physical health, self-injury is a form of bodily, psychological and cultural impurity; it is unhygienic.

While instinctive revulsion at the sight of wounds and injuries is a common human response, here it acquires an added dimension through the fact that the injury is selfinflicted. Psychologists report feeling physically threatened at the sight of self-injury wounds (Motz 2010). Becoming aware of the self-injury of others reveals to us that this is a possible way of coping with difficulties which we too may adopt, but which we may recoil from. Increasingly, selfinjury is seen as contagious (Chaney 2019), maybe because disgust often inspires fears of contagion (Ahmed 2004). Images of self-injury or even the sight of old self-harm scars are seen as potential triggers that will cause others to hurt themselves. This, of course, can add to the distress of those who have already self-injured, as now their bodies themselves suddenly appear as sites and sights of contagion (Chaney 2019).

This is implied in the cycle of self-injury commonly accepted in the literature (e.g. Sutton 2007). The cycle, as commonly described, starts with distress that becomes seemingly unbearable and generates an intense urge demanding a response. Agents respond to this urge by self-injuring, which provides relief, whether through the pain of the injury itself and other related sensory aspects such as the sight of blood, or through the self-care administered afterwards. The temporary respite that follows is eventually replaced by guilt over the self-injurious behaviour and shame about having to hide its consequences. Finally, the individual's level of distress rises again, now encompassing both the initial distressing situation and the added negative affect resulting from self-harm.

The basic narrative focuses on the individual cognition,- - both thoughts and emotions, - and ignores both the embodied meaning of self-injury and the extent to which all aspects of this cycle are socially embedded. Self-harm is an affordance fostered by society that on the one hand allows agents to remain in distressing situations and on the other hand both legitimates and prohibits self-injury as a method 
of emotional self-regulation. All stages of the cycle could also be characterised through participatory sense-making. Agents make sense of their distress through the ready-provided affordance of self-injury, and the real or internalised and expected reaction of disgust from others further fuels that distress. This serves to obscure rather than reveal some of the aspects of self-injury that are relevant for its ethical assessment. My worry is that the use of reactive attitudes such as blame to disrupt self-injury only contributes to further strengthening the hold of this behaviour in the lives of distressed people. Social norms themselves could be affordances: norms afford us the opportunity to blame others or to pressure people to desist from further self-harm. Yet this blame causes exactly the kind of distress that leads to repeated self-harm.

If we take this thought further, we can argue that human bodies are fundamentally social bodies. Even when they are on their own, in an empty flat or locked into a bathroom, a person is enmeshed in sociality. Affordances for action and emotion flow as much from the outside as they are enacted from inside a person's body-mind. By being normatively social bodies, we are also ethical bodies. Interpreting ourselves as ethical bodies opens up (at least) two possible explanations about self-injury. On the one hand, our bodies are bound by social convention, but they are also pushed by social forces against those conventions. I take this to be the idea behind the argument by Scanlon and Adlam (2009) that self-injury is never deliberately chosen or voluntary, but is rather violence against the self that society pushes someone into. On the other hand, self-injury can also be read as a deliberate resistance using the invitation for relief most immediately available — an affordance inherent in our bodies - to pressures which are either caused by, or not satisfactorily resolved by our sociality. Instead of obscuring it, an enactivist analysis helps us to reveal this complex landscape, thus enabling us to develop better ethical theories.

\section{Discussion}

My aim in this paper has been to use ideas from enactivism in order to explore self-injury without assuming a priori that it is morally or socially wrong under all circumstances, seeking to establish a less implicitly valueladen analysis. Looking at self-injury through the lens of habits can confirm us in the normative judgment that those who self-injure choose actions from their environment in the "wrong" way, even if it goes some way in understanding why it is so difficult to change from selfinjury to other modes of distress management. Looking at self-injury through the lens of affordances complicates this picture considerably by showing how cultural factors make self-injury more widely available at the same time as stigmatising it. It reminds us that our environment provides us multiple ways of interacting with our bodies and under the specific circumstances an agent faces (often a choice between two bad option, such as continuing distress or self-injury), what is bad for us is not necessarily wrong as well. Thus enactivism can shift our focus of what is salient about a behaviour.

Enactivism is here useful in two ways. Firstly, new perspectives can help us in determining how we should judge this problematic behaviour, for example by helping us understand how self-injury becomes an affordance provided not just by our material but also our social environment. This allows us to recognise the way in which our culture shapes the possibilities we see in our material environment and the contribution of our society to problematic behaviour, without neglecting the importance of individual enaction. Secondly, it directs us to aspects of self-injury which are still under-explored, making us demand deeper explanations of how the uses and benefits of the practice reported by persons who self-injure are generated and experienced. Thus while the ethics around self-injury may need re-evaluating, we simultaneously need more empirical research to do so successfully, notwithstanding the excellent qualitative studies cited in this paper.

Does this single case offer any indication of how enactivism can become a theory of sense-making particularly useful for ethical theorising? According to one influential view, moral philosophy can be conceptualised as the study of how we should treat other people (Ronald Dworkin, quoted in Appiah 2006, p. 17). By contrast, Juergen Habermas differentiates between ethics and morality, and conceptualises ethical theories as the motivational bridge between abstract moral judgment and action (Habermas 2018). For Habermas, moral discourse aims at the impartial evaluation of action conflict, whereas ethical discourse is grounded in the lifeworld of the individual, including their culture, and can accommodate egocentric and ethnocentric demands (Habermas 1996). A general rule, such as the Kantian categorical imperative might indicate that lying is morally wrong, but our culture and the position we occupy in society can lead us to believe that under certain circumstances lying is ethically permissible. Thus, it might be acceptable for a stigmatised individual to lie about their identity, as an act of passing, so as not to be excluded from the social and material goods that should be available to all. Equally, while self-injury is for the most part inappropriate, it can become culturally suggested appropriate behaviour under certain circumstances of agential distress.

This conceptualisation of the distinction between morality and ethics is useful here, as it helps us to identify a potential role for enactivism in ethics: it elucidates the way agents make sense of, and respond to the situation they are in. The question is whether applying a basically enactivist framework to our thinking about self-injury achieves anything other than 
tinkering at the margins. I believe that even in such a short space, turning to enactivism has allowed me to show that it can facilitate a greater understanding of the conflicts that those who self-injure are caught up in, both on the social level where there is a scarcity of appropriate support and affordances for self-help, and on the level of basic enaction where different motivations can clash without a satisfactory resolution. Considering self-injury as a meaningful, skilled habitual action points towards a need for not only top-down cognitive therapies, but also bottom-up embodied solutions. As a result, we can no longer view self-injury as something wholly undesirable, or as something that individuals can be made responsible for overcoming solely through willpower. Instead, it can be seen as part of the dynamics of an individual responding to and overcoming challenges raised by the environment with the help of affordances provided by that same environment. At this stage, we are back to the more familiar questions of ethics, as we can now ask what a just social environment would look like, where no one was needed to reduce distress through selfinjury, where our responses to distress, - - even if manifested through problematic behaviour,- - are not stigmatising and where better forms of distress management are just as easily available if needed.

New approaches to any subject of philosophical enquiry are never without risk. We could use an enactivist framework to take such risks and explore novel problems and novel viewpoints. If we do this, we will not aim to replace or replicate our existing ethical understanding, but instead enrich it and supplement it with new insights. The risk is that it is much easier to make theoretical missteps, make arguments that go off the rails, or what is at times even worse: arrive at conclusions which are in hindsight obvious, which offer no new revelations either in the outcome or the process of reasoning. Failed experiments can inspire others to try again where we have failed, boring experiments can kill off a new branch of enquiry too soon.

Acknowledgements I would like to thank the editor and three anonymous reviewers for helping me to improve this paper through their thoughtful advice.

\section{References}

Ahmed S (2004) The cultural politics of emotion. Routledge, New York Annas J (2008) The phenomenology of virtue. Phenom Cogn Sci 7:2134. https://doi.org/10.1007/s11097-007-9068-9

Appiah KA (2006) The politics of identity. Daedalus 135:15-22

Binns R (2020) The NHS and self-harm-a gap in care. In: Recovery in the bin. https://recoveryinthebin.org/2020/06/10/the-nhs-andself-harm-a-gap-in-care/. Accessed 2 Dec 2020

Breuning LG 2013) Self-harm in animals: what we can learn from it. In: Psychology Today. http://www.psychologytoday.com/blog/ your-neurochemical-self/201305/self-harm-in-animals-what-wecan-learn-it. Accessed 2 Nov 2020
Brook S, Horn N (2010) The meaning of self-injury and overdosing amongst women fulfilling the diagnostic criteria for 'borderline personality disorder.' Psychol Psychother Theory Res Pract 83:113-128. https://doi.org/10.1348/147608309X468211

Brossard B (2018) Why do we hurt ourselves? Understanding self-harm in social life. Indiana University Press, Bloomington

Brunning L, McKeever N (2021) Asexuality. J Appl Philos 38:497517. https://doi.org/10.1111/japp.12472

Cappuccio ML, Miyahara K, Ilundáin-Agurruza J (2020) Wax on, wax off! Habits, sport skills, and motor intentionality. Topoi 40:609622. https://doi.org/10.1007/s11245-020-09720-3

Chandler A (2016) Self-injury, medicine and society: authentic bodies. Palgrave Macmillan, London

Chaney S (2019) Psyche on the skin: a history of self-harm. Reaktion Books, London

Cholbi M (2011) Suicide: the philosophical dimensions. Broadview Press, Peterborough

Clarke L, Whittaker M (1998) Self-mutilation: culture, contexts and nursing responses. J Clin Nurs 7:129-137

Colombetti G (2014) The feeling body: affective science meets the enactive mind. MIT Press, Cambridge

Colombetti G, Krueger J (2015) Scaffoldings of the affective mind. Philos Psychol 28:1157-1176. https://doi.org/10.1080/09515089. 2014.976334

Colombetti G, Torrance S (2009) Emotion and ethics: an inter-(en) active approach. Phenomenol Cogn Sci 8:505-526. https://doi. org/10.1007/s11097-009-9137-3

de Haan S (2020) An enactive approach to psychiatry. Philos Psychiatry Psychol 27:3-25. https://doi.org/10.1353/ppp.2020.0001

De Jaegher H, Di Paolo E (2007) Participatory sense-making. Phenom Cogn Sci 6:485-507. https://doi.org/10.1007/s11097-007-9076-9

DeSouza N (2013) Pre-reflective ethical know-how. Ethic Theory Moral Pract 16:279-294. https://doi.org/10.1007/s10677-012-9333-z

Di Paolo EA, Cuffari EC, De Jaegher H (2018) Linguistic bodies: the continuity between life and language. MIT, Cambridge

Douglas M (1966) Purity and danger an analysis of concept of pollution and taboo. Routledge, London

Elias N, Dunning E, Goudsblom J, Mennell S (2000) The civilizing process: sociogenetic and psychogenetic investigations. Blackwell, Oxford

Gallagher S (2020) Action and interaction. Oxford University Press, New York

Giordano S (2019) Anorexia nervosa: a case for exceptionalism in ethical decision making. Philos Psychiatry Psychol 26:315-331. https://doi.org/10.1353/ppp.2019.0047

Glas G (2020) An enactive approach to anxiety and anxiety disorders. Philos Psychiatry Psychol 27:35-50. https://doi.org/10.1353/ppp. 2020.0005

Habermas J (1996) Between facts and norms: contributions to a discourse theory of law and democracy. MIT, Cambridge

Habermas J (2018) Philosophical introductions: five approaches to communicative reason. Polity, Cambridge

Hacking I (1998) Mad travelers: reflections on the reality of transient mental illnesses. University Press of Virginia, Charlottesville

Heidegger M (1953) Being and time. State University of New York Press, Albany

Herman JL (2015) Trauma and recovery, 2015th edn. Basic Books, New York

Husserl E (2012) Ideas: general introduction to pure phenomenology. Routledge, London

Kant I (1797) The metaphysics of morals. Cambridge University Press, Cambridge

Kiverstein J, Clark A (2009) Introduction: mind embodied, embedded, enacted: one church or many? Topoi 28:1-7. https://doi.org/10. 1007/s11245-008-9041-4 
Klonsky ED (2011) Non-suicidal self-injury in United States adults: prevalence, sociodemographics, topography and functions. Psychol Med 41:1981-1986. https://doi.org/10.1017/S003329171 0002497

Kong C (2019) Nurture before responsibility: self-in-relation competence and self-harm. Philos Psychiatry Psychol 26:1-18. https:// doi.org/10.1353/ppp.2019.0000

Krueger J (2014) Affordances and the musically extended mind. Front Psychol. https://doi.org/10.3389/fpsyg.2013.01003

Loaiza JM (2019) From enactive concern to care in social life: towards an enactive anthropology of caring. Adapt Behav 27:17-30. https://doi.org/10.1177/1059712318800673

MacIntyre AC (2009) Dependent rational animals: why human beings need the virtues. Duckworth, London

Maiese M (2021) Autonomy, enactivism, and psychopathy. Philos Explor. https://doi.org/10.1080/13869795.2021.1937680

Mauss M (1973) Techniques of the body. Econ Soc 2:70-88

McClelland T (2020) The mental affordance hypothesis. Mind 129:401-427. https://doi.org/10.1093/mind/fzz036

Merleau-Ponty M (1968) The visible and the invisible: followed by working notes. Northwestern University Press, Evanston

Miyahara K, Robertson I (2021) The pragmatic intelligence of habits. Topoi 40:597-608. https://doi.org/10.1007/s11245-020-09735-w

Mojica L, Gastelum Vargas M (2021) The affective and normative intentionality of skilled performance: a radical embodied approach. Synthese. https://doi.org/10.1007/s11229-021-03159-8

Motz A (2010) Self-harm as a sign of hope. Psychoanal Psychother 24:81-92

Muehlenkamp JJ, Claes L, Havertape L, Plener PL (2012) International prevalence of adolescent non-suicidal self-injury and deliberate self-harm. Child Adolesc Psychiatry Ment Health. https://doi.org/ 10.1186/1753-2000-6-10

Muñoz D (2020) The paradox of duties to oneself. Australas J Philos 98:691-702. https://doi.org/10.1080/00048402.2019.1697711

Nielsen K (2021) Comparing two enactive perspectives on mental disorder. Philos Psychiatry Psychol 28:175-185. https://doi.org/10. 1353/ppp.2021.0028

Pacherie E (2008) The phenomenology of action: a conceptual framework. Cognition 107:179-217. https://doi.org/10.1016/j.cognition. 2007.09.003

Pickard H (2015) Self-harm as violence: when victim and perpetrator are one. In: Widdows $\mathrm{H}$, Marway $\mathrm{H}$ (eds) Women and violence: the agency of victims and perpetrators. Palgrave Macmillan, London

Pickard H (2020) Addiction and the self. Noûs. https://doi.org/10.1111/ nous. 12328

Ramírez-Vizcaya S, Froese T (2019) The enactive approach to habits: new concepts for the cognitive science of bad habits and addiction. Front Psychol. https://doi.org/10.3389/fpsyg.2019.00301

Rietveld E, Kiverstein J (2014) A rich landscape of affordances. Ecol Psychol 26:325-352. https://doi.org/10.1080/10407413.2014. 958035
Rossi Monti M, D’Agostino A (2019) Dysphoria in borderline persons. In: Stanghellini G, Broome M, Raballo A et al (eds) The Oxford handbook of phenomenological psychopathology. Oxford University Press, pp 826-838

Rucińska Z (2021) Enactive planning in rock climbing: recalibration, visualization and nested affordances. Synthese. https://doi.org/10. 1007/s11229-021-03025-7

Scanlon C, Adlam J (2009) Why do you treat me this way?": reciprocal violence and the mythology of 'deliberate self harm. In: Motz A (ed) Managing self-harm, 1st edn. Routledge, London

Schiavio A, van der Schyff D, Cespedes-Guevara J, Reybrouck M (2017) Enacting musical emotions. Sense-making, dynamic systems, and the embodied mind. Phenomenol Cogn Sci 16:785-809. https://doi.org/10.1007/s11097-016-9477-8

Schutte O (1998) Cultural alterity: cross-cultural communication and feminist theory in north-south contexts. Hypatia 13:53-72. https:// doi.org/10.1111/j.1527-2001.1998.tb01225.x

Seaber E (2016) Reading disorders: pro-eating disorder rhetoric and anorexia life-writing. Lit Med 34:484-508. https://doi.org/10. 1353/lm.2016.0023

Sharma VK, Rango J, Connaughton AJ et al (2015) The current state of head and neck injuries in extreme sports. Orthop J Sports Med 3:2325967114564358. https://doi.org/10.1177/2325967114 564358

Siegel S (2014) Affordances and the contents of perception. In: Brogaard B (ed) Does perception have content? Oxford University Press, pp 51-75

Steggals P (2015) Making sense of self-harm the cultural meaning and social context of nonsuicidal self-injury. Palgrave, London

Sutton J (2007) Healing the hurt within: understand self-injury and self-harm, and heal the emotional wounds. How To Books, Oxford

Svenaeus F (2021) Health and illness as enacted phenomena. Topoi. https://doi.org/10.1007/s11245-021-09747-0

Urban P (2016) Foregrounding the relational domain-phenomenology, enactivism and care ethics. Horizon Stud Phenomenol 5:171182. https://doi.org/10.18199/2226-5260-2016-5-1-171-182

van Grunsven J (2018) Enactivism, second-person engagement and personal responsibility. Phenom Cogn Sci 17:131-156. https:// doi.org/10.1007/s11097-017-9500-8

van Dijk L, Rietveld E (2017) Foregrounding sociomaterial practice in our understanding of affordances: the skilled intentionality framework. Front Psychol 7:1969. https://doi.org/10.3389/fpsyg. 2016.01969

Varela FJ (1999) Ethical know-how: action, wisdom, and cognition. Stanford University Press, Stanford

Publisher's Note Springer Nature remains neutral with regard to jurisdictional claims in published maps and institutional affiliations. 